\title{
As Coisas-memória na Arte da Performance
}

\author{
Las Cosas-memoria en el Arte del Performance
}

\author{
The Things-memory in the Performance Art
}

\author{
Tatiana dos Santos Duarte ${ }^{1}$ \\ Eduarda Azevedo Gonçalves ${ }^{2}$
}

\begin{abstract}
Resumo
A pesquisa intitulada "As coisas-memória na arte da performance" desenvolvida no PPGAVI/UFPel é vinculada à linha de pesquisa Processo de Criação e Poéticas do Cotidiano, sob orientação da Profa. Dra. Eduarda Gonçalves e versa sobre o processo poético da performance como resultado de resgate de memórias vividas no contexto familiar e adquiridas no contato com produções artísticas. A prática artística desta pesquisa, em específico nos seus processos performáticos, conduz ao conceito de coisas-memória imbricando a linguagem das artes visuais e da dança. A reflexão é articulada à produção de performance evidenciando o conceito de coisa, revisto por Foucault e Deleuze, assim como o conceito de memória evidenciado pelo filosofo Henri Bergson. Colocando questões do presente e de um passado (infância com a avó, através de vídeos, objetos, roupas e fotografias), o conceito de coisas-memória reinventa as percepções ao se tornar ação performática. As vestimentas e objetos são algumas das visibilidades que vão dar a ver as dizibilidades expressadas nos atos em performances. Por estas questões se versa sobre duas performances realizadas: $\mathrm{O}$ que é daqui? Processos e Trajetos; Voz e Matéria, são igualmente evidenciadas nas referências artísticas de Marina Abramovic e Sophie Calle, abordando aspectos referentes à linguagem da performance que tem como disparo as relações interpessoais e da memória.
\end{abstract}

Palavras-Chave: Arte Contemporânea; Coisas-memória; Performance; Poéticas Visuais.

\section{Resumen}

La investigación titulada "Las cosas-memoria en el arte de la performance" desarrollada en el PPGAVI / UFPel está vinculada a la línea de investigación Proceso de Creación y Poéticas del Cotidiano, bajo orientación de la Profa. Dra. Eduarda Gonçalves y versa sobre el proceso poético de la performance como resultado de rescate de memorias vividas en el contexto familiar y adquiridas en el contacto con producciones artísticas. La práctica artística de esta investigación, en específico en sus procesos performáticos, conduce al concepto de cosasmemoria imbricando el lenguaje de las artes visuales y de la danza. La reflexión es articulada a la producción de performance evidenciando el concepto de cosa, revisado por Foucault y Deleuze, así como el concepto de memoria evidenciado por el filosofo Henri Bergson. En el caso de las mujeres, la mayoría de las veces, la mayoría de las veces, la mayoría de las veces, la mayoría de las veces, la mayoría de las veces, Las vestimentas y objetos son algunas de las visibilidades que van a dar a ver las afirmaciones expresadas en los actos en performances. Por estas cuestiones se trata sobre dos performances realizadas: ¿Qué es de aquí? Procesos y Trayectos; La voz y la materia, son igualmente evidenciadas en las referencias artísticas de Marina Abramovic y Sophie Calle, abordando aspectos referentes al lenguaje de la performance que tiene como disparo las relaciones interpersonales y de la memoria.

Palabras claves: Arte Contemporáneo; Cotidiano; Memoria; Performance; Poéticas Visuales.

\section{Abstract}

\footnotetext{
${ }^{1}$ Mestranda em artes visuais pelo Programa de Pós-graduação da Universidade Federal de Pelotas;Pelotas; RS; Brasil; hecateciclops@yahoo.com.br

${ }^{2}$ Doutora pelo Programa de Pós-Graduação do Instituto de Artes da Universidade Federal do Rio Grande do Sul

- UFRGS, Porto Alegre; RS; Brasil; dudaeduarda.ufpel@gmail.com
} 
The research entitled "The memory-stuff in the art of performance" developed in the PPGAVI / UFPel is linked to the line of research Process of Creation and Poetics of Daily Life, under the guidance of Profa. Dra. Eduarda Gonçalves and on the poetic process of performance as a result of the rescue of memories lived in the family context and acquired in contact with artistic productions. The artistic practice of this research, specifically in its performative processes, leads to the concept of memory-things imbricating the language of visual arts and dance. The reflection is articulated to the production of performance evidencing the concept of thing, reviewed by Foucault and Deleuze, as well as the concept of memory evidenced by the philosopher Henri Bergson. By putting issues of the present and the past (childhood with the grandmother, through videos, objects, clothes and photographs), the concept of memory-things reinvents perceptions by becoming performative action. The clothes and objects are some of the visibilities that will give to see the dizibilities expressed in the acts in performances. For these questions it is about two performed performances: What is it from here? Processes and Paths; Voice and Matter, are also evidenced in the artistic references of Marina Abramovic and Sophie Calle, addressing aspects related to the language of performance that has as a trigger the interpersonal and memory relations.

Keywords: Contemporary Art; Daily Life; Memory; Performance; Visual Poetry.

\section{Introdução}

A pesquisa em andamento, desenvolvida no Programa de Pós-Graduação Mestrado em Artes Visuais da Universidade Federal de Pelotas, na linha de pesquisa Processos de Criação e Poéticas do Cotidiano sob orientação da Profa. Dra. Eduarda Gonçalves, versa sobre o processo de criação em arte contemporânea e performance por meio de revisitação das memórias pessoais. O desenvolvimento da produção artística direciona-se ao encontro de relações das coisas-memória do cotidiano. Este tex to foi escrito a quatro mãos, mas adotou-se a primeira pessoa do singular como forma de escrita, sendo a memória da artista Tatiana bordada e zelada por Eduarda.

O método empregado para esta pesquisa segue os conceitos de Sandra Rey, que diz que na arte, mais especificamente nas poéticas visuais, mensura-se toda uma gama de procedimentos, onde "a metodologia de trabalho em atelier leva em conta a obra como processo [...] ao mesmo tempo um processo de formação e um processo no sentido de processamento, de formação de significado" (REY, 1996, p. 85). Assim, vejo o atelier em meu corpo, que na performance vai transformando em sentidos e significados as memórias que ganham movimentos e corporeidades. Busco uma rede de conceitos para dar conta destes processos de minha prática em performance; na teoria busco matérias para compor com a técnica o que as obras propõem. Também se estabelece relações com a história da arte e com a produção contemporânea, colocando o pesquisador em artes visuais a escrever diferentemente dos filósofos, historiadores e críticos de arte, dando potência à escrita de maneira que tenha tamanha importância sobre estes. Cunhado para caracterizar o pensamento que dá vazão ao desenvolvimento das performances e, assim, estabelecer uma produção de sentido da poética artística. Com isso, se explicita na presente pesquisa reflexões acerca das performances $O$ que é daqui? Processos e trajetos e Voz e Matéria. 
O pensamento acerca do conceito de coisas-memória nas performances evidencia as memórias de infância da minha Avó, para dar luz ao apagamento do tempo de uma mulher simples do campo e de descendência indígena. As recordações são colocadas em movimento, ao processar a performance e durante sua realização, então ganham força e saem do meio da massa para vir para margem (DELEUZE; GUATTARI, 2011). A memória é abordada como memória-hábito e lembrança-pura, conceituadas pelo filósofo Henri Bergson (2010). Ao resgatar as memórias familiares e incluí-las no processo de criação é possível acionar algumas lembranças-puras (BERGSON, 2010) que vêm à tona, possibilitando entender os processos que me constituíram e que passam a constituir meu trabalho artístico.

Igualmente, conjugado aos pensadores que me elucidam alguns conceitos, aponto como referência artística para ampliar o pensamento e contextualizar o trabalho na produção contemporânea, a artista sérvia Marina Abramovic, pela performance The Lovers - The Great Wall Walk (1988) e uma série posterior, desdobramento desta, intitulada Transitory Objetcs for Human (1991). A artista utiliza o corpo e objetos, "havia trazido comigo alguns desses belos minerais que encontrei lá: quartzo rosa, quartzo cristalino" (ABRAMOVIC, 2017, p. 225), que de certa maneira me concede a base para refletir sobre o uso de objetos significativos que serão potência para deixar subir memórias à superfície.

A artista Sophie Calle, fotógrafa francesa, é aludida como referente, fundamentalmente pela obra Cuide de Você (CALLE, 2016), em que conjuga trabalhos como uma maneira de "narrar uma autobiografia afetiva" (D'ANGELO, 2015, p. 202). Relaciono a performance Voz e Matéria com a exposição de Calle, em que a artista envolve o outro na realização da performance, atenuando as fronteiras entre as memórias pessoais e a partilha com o outro.

As memórias como um mote para performar e os processos de interação com o público são uma tática artística que, segundo Ronaldo Brito, dão a ver que "há provavelmente uma urgência de uma maior mobilidade na prática dos artistas [...] uma mobilidade tática, voltada para fora - sem prejuízo, é claro, do rigor de articulação interna do trabalho" (BRITO, 1975, p. 6 apud FUREGATTI, 2016, p. 2024). Assim, faço delas uma força para movimentar-me pelos territórios além da memória, como uma espécie de acionamento do movimento do fazer, implicando gestos performáticos, imagens e proposições no contexto de apresentação artística.

O processo envolve a rememoração e o deslocamento físico na cidade de Pelotas para encontrar pistas que me deem os contornos das lembranças que me habitam e que muitas vezes não estão claras e tampouco prontas para serem compartilhadas. O caminhar é um meio 
RELACult - Revista Latino-Americana de Estudos em Cultura e Sociedade

Revista Latinoamericana de Estudios en Cultura y Sociedad | Latin American Journal of Studies in Culture and Society V. 05, ed. especial, abr., 2019, artigo no 1151 | claec.org/relacult |e-ISSN: 2525-7870

pelo qual encontro "a forma" das lembranças, fundamentalmente encontro objetos e os utilizo em ações artísticas. Assim, coloco um corpo na cidade, ativo e propositivo, a fim de pensá-la como formadora de subjetividades. E então a questão de pesquisa surge para incitar o pensamento: Como que as recordações pessoais e a cidade, continente de espaços, objetos e fatos transformam-se em coisas-memória na performance?

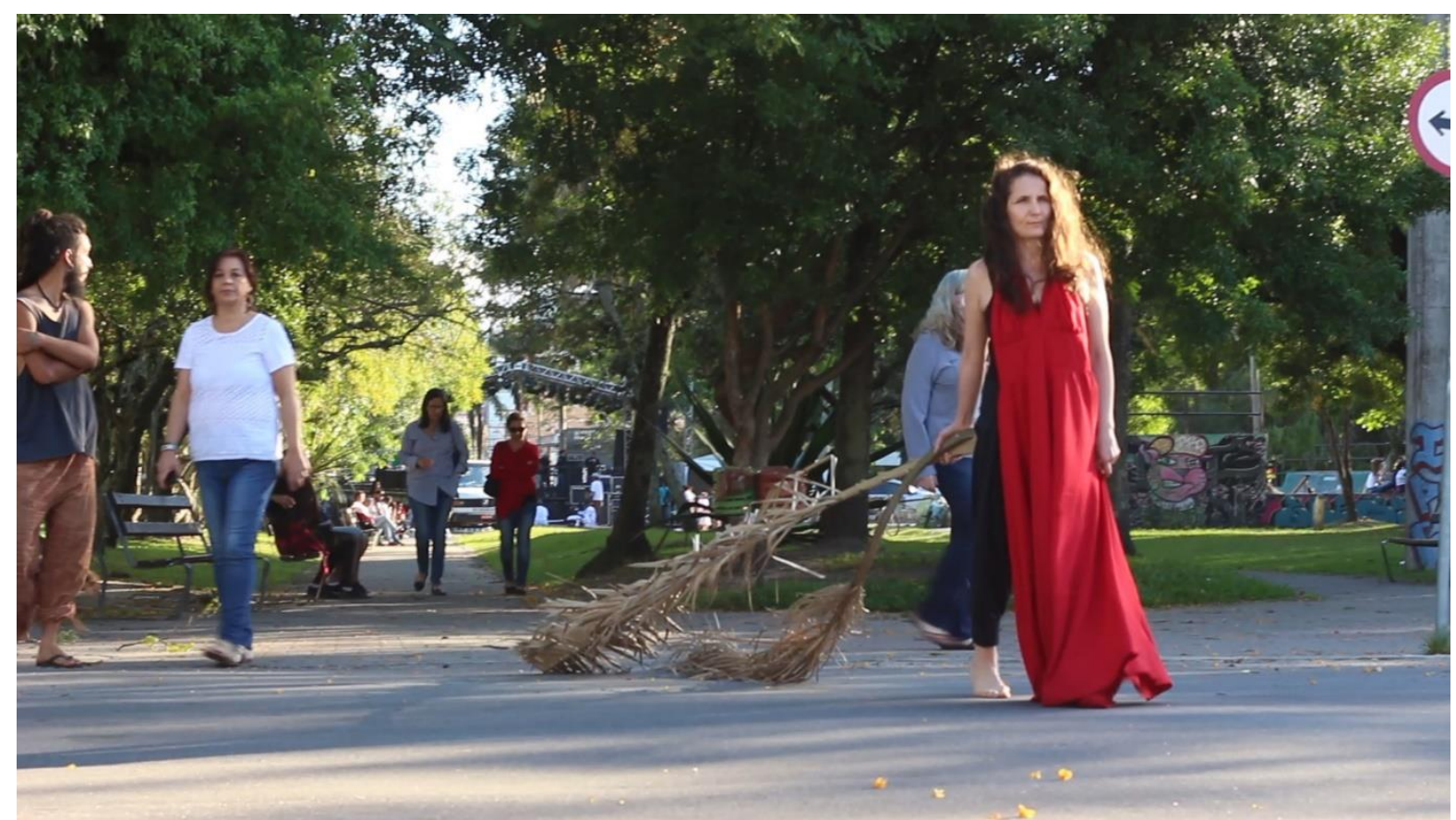

Figura 1: Performance $O$ que é daqui?, 2017. Fonte: arquivo pessoal.

\section{Método}

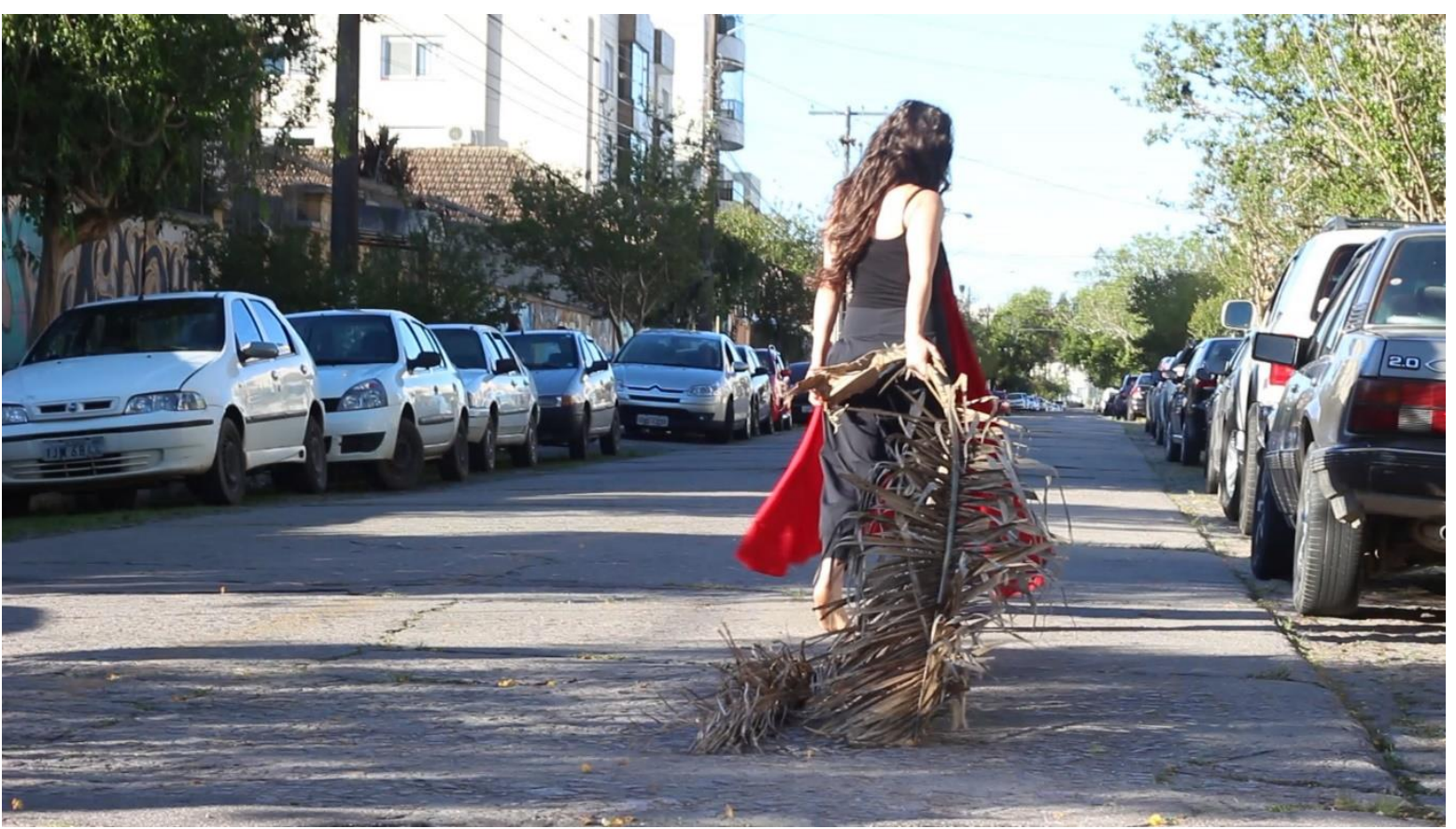


Figura 2: Performance $O$ que é daqui?, 2017.

Fonte: arquivo pessoal.

Uso como método de pesquisa a pesquisa em poéticas visuais. Segundo Sanda Rey: “A pesquisa em arte vai encontrar respaldo teórico na poiëtica, que propõe-se como uma ciência e filosofia da criação, levando em conta as condutas que instauram a obra" (REY, 1996, p. 83).

Ou seja, a prática e a teoria me auxiliam a movimentar a criação, os conceitos que me conduzem à reflexão e à teoria da arte evidenciando que o artista ao mesmo tempo que processa a obra é processado por ela.

Se na ciência os pesquisadores e cientistas costumam trabalhar em bloco, e se empenham na decodificação de fatos e interpretação de conceitos que permitam organizar o entendimento da realidade e descobrir princípios que regem o mundo e o universo, na arte, o artista segue ou inventa um certo número de regras que lhe permitem criar uma visão de mundo singular". (REY, 1996, p. 83)

Partindo de leituras e da prática do fazer performático acesso as memórias que em mim habitam e se atualizam, as memórias dos acontecimentos vividos com minha avó, como preceito também de resistir ao apagamento de pessoas. Assim como o caminhar na praça de Pelotas, com estado de atenção para criação, encontro objetos e seres que existem neste espaço. Pelo trajeto acho as coisas-memória que estão no campo do processo, encontro a folha de palmeira (que estava no chão depois de ventos fortes) e percorro um caminho que aciona memórias e estados de criação.

A artista Marina Abramovic me auxilia na compreensão sobre aspectos de meu processo de criação. Ao traçar uma afinidade com a performance The Lovers - The Great Wall Walk (1988) e a série de peças Transitory Objetcs for Human Use (1991), a artista percebe os minerais na caminhada e como estes interferiam em seu estado e no processo. Abramovic coleta quartzo rosa, quartzo cristalino, ametista e obsidiana na muralha da China e faz com que as pedras se transformem na referida série artística.

$\mathrm{O}$ deslocamento e o encontro com esses materiais me conduzem às similitudes com o procedimento de Abramovic, partindo também de uma caminhada e encontro com objetos da natureza. Na ação conecto-me ao estar atenta aos processos e suas sutilezas no percurso que me proponho estar para que me afetem e orientem movimentos da performance.

Percebendo como estes lugares possibilitam processos e encontros com a criação artística, ao deslocar-me os trajetos (mesmo que uns percursos pequenos) se colocam como um campo de experimentação e relação de tempo e ambiente dos seres e um campo de experimentação do corpo com a cidade. Ao caminhar com um olhar atento ao passar por objetos, deixo minha intuição revelar as coisas-memórias da rua. 


\section{Resultados e Discussões}

Ao me deslocar estou atenta, passo por uma folha de palmeira e nela encontro força para interagir e pensar o local urbano. Nas pisadas com a câmera na mão, olhando através do celular, me deparo com árvores, raízes, folhas, até encontrar o objeto que será o formador de minhas lembranças, que darão forma a memórias que ainda não consigo partilhar. Assim, o ato de performance traz questões da memória como um mar de dentro, os relatos de história da minha mãe. Ela contava que quando morava na cidade de Lajeado brincava de balanço nas folhas de palmeiras, me colocando a pensar sobre estes lugares e como eles fazem relação com os objetos que pertencem. A partir disto, a cidade e seus objetos vão acionando desejos de performar com as recordações que me trazem. Faço esse deslocamento como uma forma de colocar no corpo uma força para resgatar as coisas-memória.

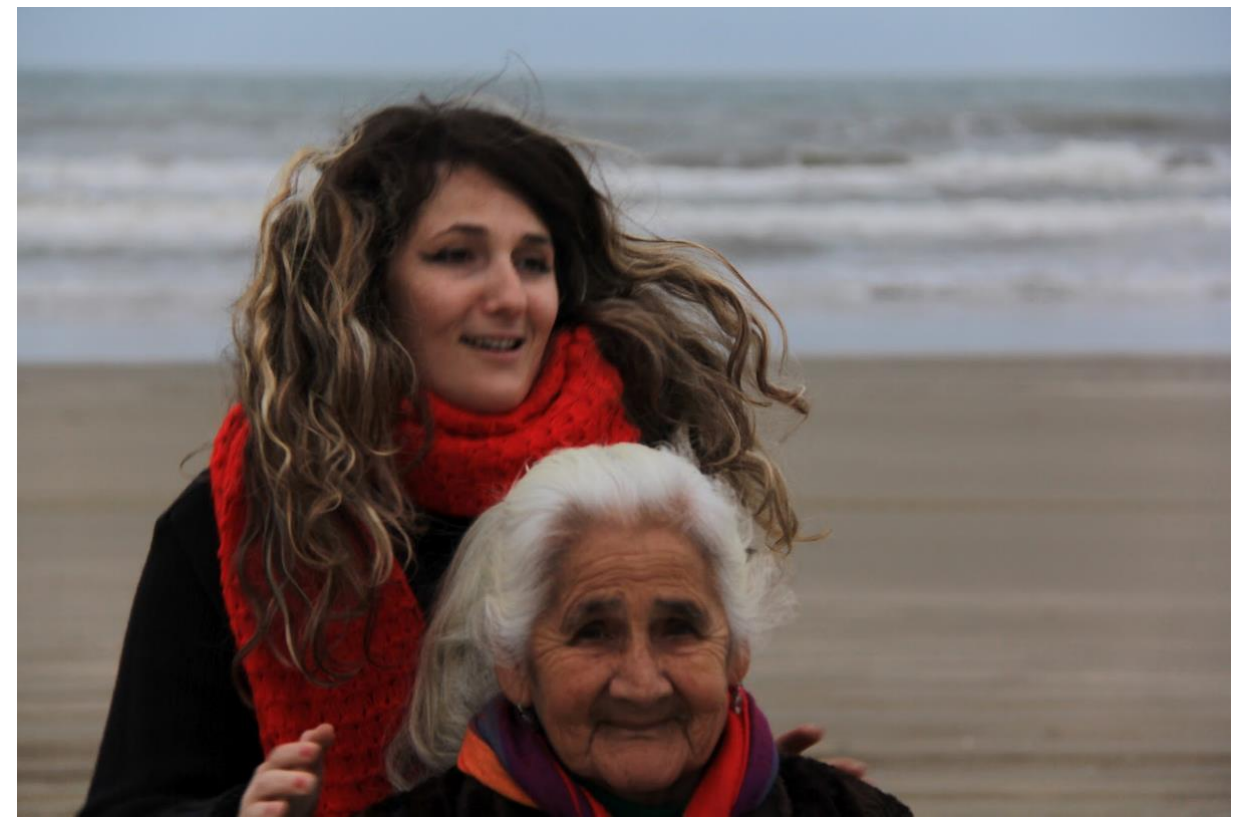

Figura 3: Avó e relação com o Mar de dentro, 2012.

Fonte: arquivo pessoal.

Surgem pistas, e por elas eu me desloco e experimento. Minha avó e o mar aparecem constantemente, e ao encontrar e arrastar a folha de palmeira que estava no chão da praça, revelam-se ruídos litorâneos. Assim, memórias vindas do Cassino e a história contada pela minha mãe na minha infância surgem não por acaso, pois ao perceber isto relaciono lugares nos quais passei com meu corpo: estão em conexão com questões a serem ditas. Vou ao encontro das relações das coisas-memória do cotidiano e, assim, estabeleço uma produção de sentido singular em minha poética artística. 
Investigar este processo poético é resgatar memórias que não são facilmente localizáveis. No ato, pela execução de ações com o corpo, uma prática de vida em obra se mostra. Ao utilizar objetos e vídeo como olhar, os processos poéticos se tornam um meio/obra da Performance. As memórias que surgem durante as performances ganham força pela lembrança e atualizam o presente. Assim chego num relato de minha avó sobre a morte de sua mãe (minha bisavó), que ao se deslocar de uma aldeia indígena para outro local, foi caçada e morta por estancieiros na cidade de Lajeado.

A performance abordada aqui revela-se como encontro nas definições de memóriahábito e da lembrança-pura elencadas por Henri Bergson (2010) - são motivações de meus fazeres artísticos. O filósofo diz que a memória se divide nestes dois aspectos principais, mas que não são dicotômicos pois se aproximam e são movimentados juntos. A partir desta conceituação trago à tona as coisas-memória do cotidiano, colocando inquietações do presente e de um passado. A ação precisa estar afiada com a intuição, ela não é evidente, mas conforme a proposição se faz, vai se localizando os pontos e as linhas que se ligam aos objetos, ao meu gesto.

A coisa (FOUCAULT, 2017) ainda carece de forma, mas surge como sensação. Para Gilles Deleuze (2008) lendo Michel Foucault, as coisas e palavras são efeitos, coisas (visíveis) e palavras (dizíveis). Este pensamento ajuda a formar um conceito de coisa: aquela que não consegue ser dita e precisa do esforço da arte para ajudar a dar contorno. A partir das memórias de infância com minha avó e das lembranças que permeiam este passado, vêm à tona movimentos, gestos, objetos, vestimentas e lugares que se transformam em coisas.

A repetição, execução da mesma ação múltiplas vezes, torna-se uma memória-hábito. Imprime na memória lembranças, acontecimentos que, por se acumularem, vêm à superfície de maneira automática, quase sem pensar. Aprendemos a caminhar com muito esforço repetitivo, logo sabemos, não pensamos mais sobre os passos dados, eles entram em nossos corpos de maneira a aliviar a tensão de ter que relembrar tudo a todo momento.

Antes de que se tornem um hábito - pela importância em seus aspectos afetivos ou pela experiência que proporcionaram - as lembranças puras ou memória-imagem são forças que movem e resgatam os acontecimentos para o presente. Esses acontecimentos são registrados em nossas mentes, e Bergson nos confere que:

A primeira [forma de memória] registraria, sob forma de imagens-lembranças, todos os acontecimentos de nossa vida cotidiana à medida que se desenrolaram; ela não negligenciaria nenhum detalhe; atribuiria a cada fato, a cada gesto, seu lugar e sua data. Sem segunda intenção de utilidade ou de aplicação prática, armazenaria o passado pelo mero efeito de uma necessidade natural (BERGSON, 2010, p. 88). 
As lembranças podem surgir de estímulos a fim de presentificá-las e "do fato que uma sensação rememorada torna-se mais atual quando sentimos melhor seu peso, que a lembrança da sensação era esta sensação nascente" (BERGSON, 2010, p. 158-159). As formas de memória dialogam e se relacionam, não havendo grau de importância e, sim, potência pela justaposição.

Quando chego nas memórias de minha avó, o cheiro de massa de pão me remete à infância e a lugares de conforto que este sentido desencadeia na percepção. Uma forma de memória-hábito se faz pela lembrança pura, uma sensação vem à tona não igual, mas em diferente grau, conforme a intensidade do estímulo que me proponho.

Lembrar tem muito a ver com esquecer, e para pensar o conceito, uma memória-hábito é feita pela repetição, execução da mesma ação múltiplas vezes, tornando-se um hábito, já a lembrança pura (ou memória-imagem como Bergson às vezes menciona) são as forças que movem e resgatam os acontecimentos para o presente.

Passando por várias memórias, algumas são capazes de transportar para uma lembrança, e no meu caso foi o mar e como ele me deixa em estado atento. Acesso sensações, fazendo associação da infância e dos cafunés que minha avó me fazia, acariciando meus cabelos e como o tempo se alongava neste gesto de carinho dela.

Portanto a performance traz questões da memória, do mar de dentro, colocando a pensar a cidade por estes fluidos corporais, que nos constem dentro deste lugar cidade, organismos vivos. Partindo do encontro com o objeto-coisas-memória se dá o processo, e como se desvela a ação, propiciada pela experimentação. Busco então encontrar uma cidade pelos deslocamentos performáticos, e resgato memórias para dar forma tanto a minha memória, quanto a uma cidade que se desvela em minhas performances. Na performance $\mathrm{Voz}$ e Matéria, uma mulher e um homem com roupas sociais, cores básicas, como preto e branco, uma tesoura na mão de cada um, na rua, cada um de um lado, opostos ficam se olhando por um tempo, contamos até dez, ao longe, e ao menor movimento começam a se aproximar, caminham um em direção ao outro com passos lentos, chegam ao ponto pré-determinado e começam a falar e cortar as roupas um do outro. Terminando, ficam apenas de roupas intimas e saem juntos, fim da ação (fig. 4).

Essa é a descrição de uma atividade que criei, que já havia feito anteriormente em 2013. Ainda me é muito cara a performance, é com ela que consigo sair de bloqueios criativos e me colocar em movimento: ela é uma espécie de performance renovadora de forças. Penso nela como um lugar de me colocar em potência de pensamento, de corpo e de memórias. Não 
exatamente como uma cura, mas como processo de conseguir dizer e expressar coisas não ditas.

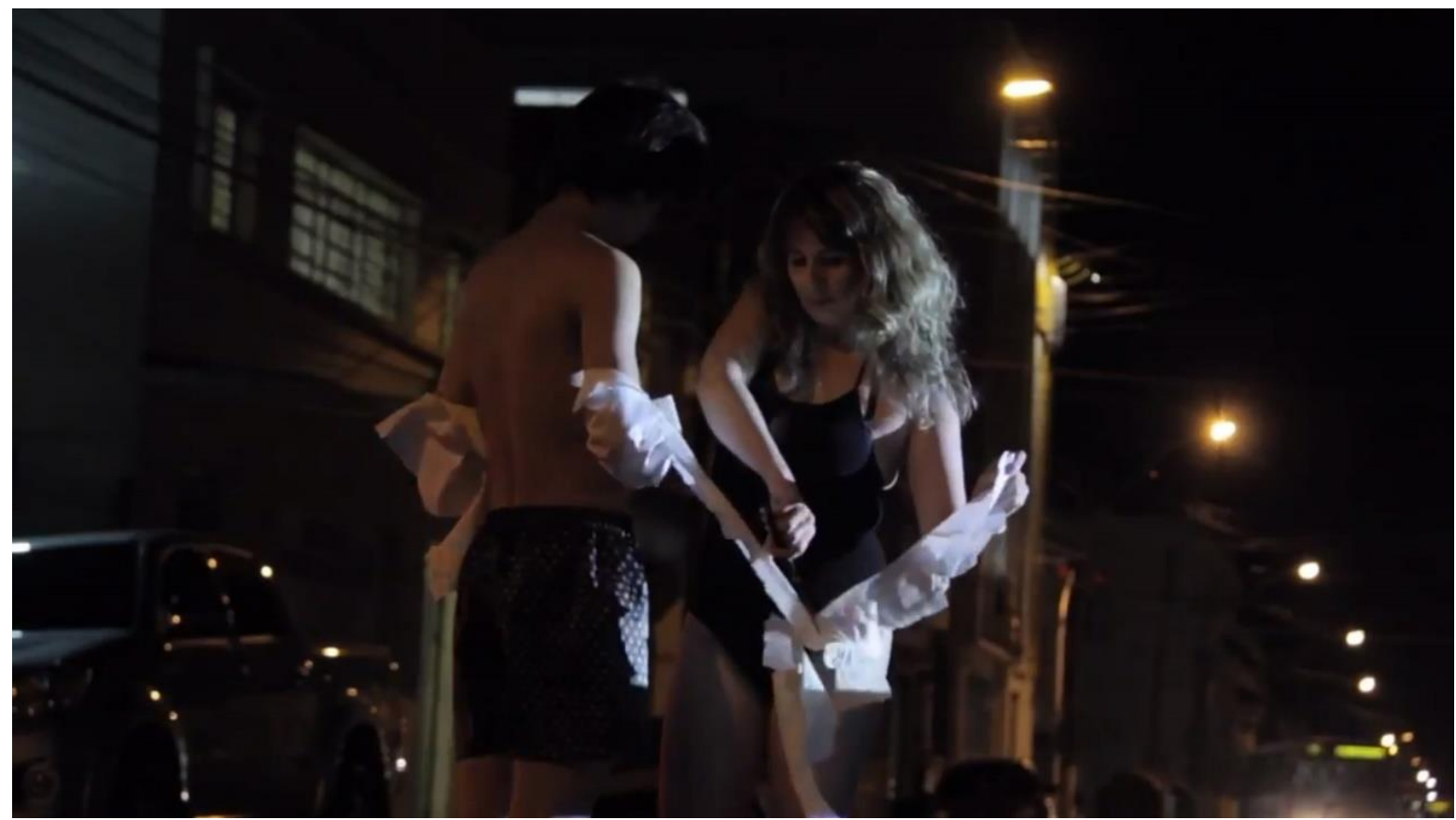

Figura 4: Frame da vídeo-performance Voz e Matéria, 2013.

Fonte do vídeo: https://goo.gl/SHs6vB.

Em 2013 convidei Lumilan Noda, um colega de teatro para fazer esta performance. Pensei na época em encontros performáticos que sensibilizassem o corpo e entoassem a criação. Surgiram alguns estímulos, começamos a fazer algumas práticas. A ação, intitulada Voz e Matéria, se origina na necessidade de experimentação. Sentíamos dores de garganta, uma espécie de bloqueio do corpo sobre algo desconfortável, talvez pela pressão social no ato de falar. Assim, propus um experimento/atividade: falar sem parar por meia hora, começando dentro da sala de ensaio e saindo para rua, dando a volta na quadra.

Agora, em 2018, refaço a performance a partir daquela experiência, e chego numa atividade que resulta nesse ato, compartilhando relações sensíveis e pessoais de cada um de nós com o público. Nesta primeira apresentação, as inquietações eram um caminho de experiência. As roupas vieram como símbolos de aprisionamento em comportamentos esperados socialmente, roupas sociais, vestido longo preto, calça preta com camisa branca e sem sapatos, as retiradas de camadas sociais. Naquela época as questões de performance eram outras.

Depois de seis anos da criação volto a performá-la. Voz e Matéria coloca a voz nas memórias, pensando em questões do passado, da infância e da memória recente em meio às coisas do presente. Parto da memória pensando sobre os caminhos que a pesquisa leva, dando 
voz aos processos, e compreendo as coisas não ditas (ou o que gostaria de falar para as pessoas e nunca consegui dizer).

Faço isso, pois preciso conectar-me com o presente e estimular-me com outros processos de sensibilização. Compartilhei com Lumilan, parceiro de arte que me acompanha há anos, a leitura de alguns textos, especialmente dois, usados como mote, um de Jacques Derrida, O Papel Máquina (2004), e outro de Ana Bernstein, Performance Solo e o Sujeito Autobiográfico (2001). Estas leituras impulsionam a memória, ajudam neste pensamento para ativá-la. Lemos os textos e deixamos que reverberassem em nossas lembranças, atualizando o passado e nos deixando mais receptíveis sobre o que ia ser escrito no papel: a experiência de trazer à tona coisas não ditas.

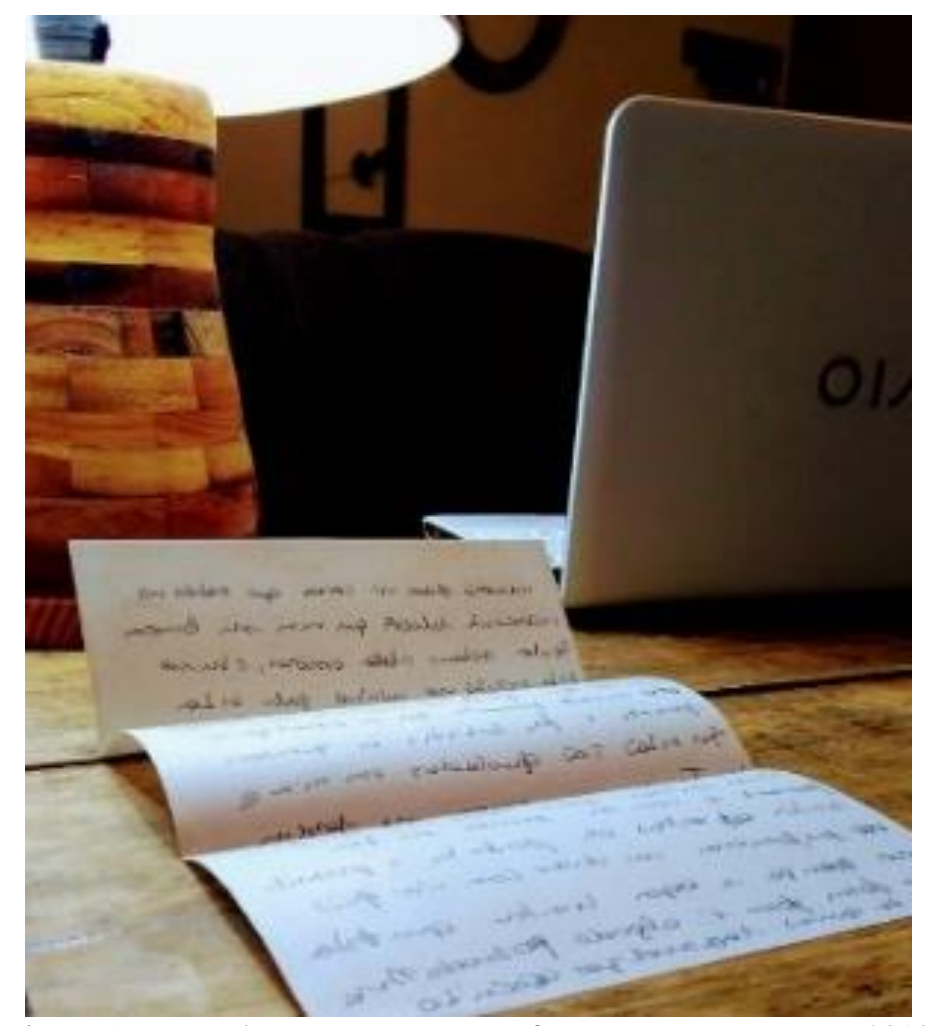

Figura 5: Textos do processo para a performance Voz e Matéria, 2018 Fonte: arquivo pessoal.

Partimos para um experimento que os surrealistas tanto fizeram, uma escrita automática (fig.05), escrever sem parar, sem pontuar, deixando sair tudo sem julgamentos, nem racionalização. Utilizamos essa escrita como recurso para desenvolver um processo de entrega, colocando a mente para resgatar coisas que precisavam ser atualizadas.

Cada um de nós tinha papel e caneta, e começamos a pensar nas memórias recentes, sem filtrar o que a escrita suscitava, escrever sem parar até o fim da folha, uma escrita contínua, sem pausas e julgamentos gramaticais. Logo após, leríamos um para o outro, deixando viva a experiência que naquele momento passamos. Depois desse exercício de 
escrita, nos arrumamos e fomos até o local da performance (seria na rua), a ida a pé era como veículo de estímulos sensíveis, para estarmos naquele lugar com toda potência. Antes de sair de casa, combinamos que durante o percurso falaríamos sem parar, dizendo tudo o que se passava em nossas mentes. Dessa forma, nos aproximamos da redação, mas com algumas variações, falas lentas, respiros, aceleramentos onde achamos que era preciso.

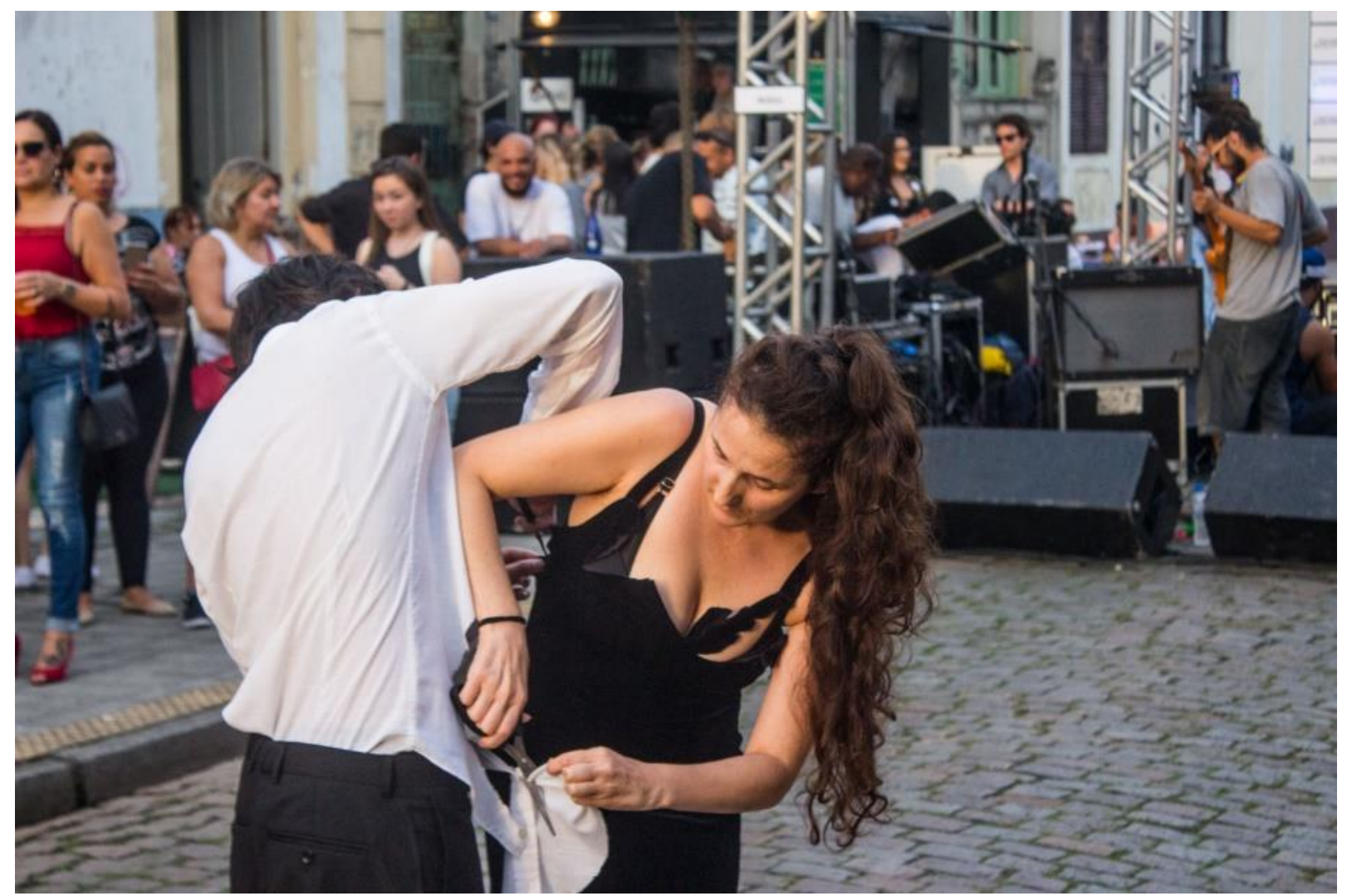

Figura 6: Performance Voz e Matéria apresentada na Fashion Revolution de Pelotas, 2018 Fonte: arquivo pessoal.

Memórias surgiram durante a performance: uma cidade onde tem mar; minha vinda para Pelotas; a morte de minha avó; a morte recente de um amigo. A morte do amigo tranca a garganta, não conseguia mais falar, estava com um nó, não conseguia mais dizer (ainda tenho que pensar nas coisas não ditas). Cortando a roupa do colega (fig. 06) fui deixando esta sensação reverberar pelo corpo e, naquele momento, fiquei sozinha na rua, neste retorno a mim, olhei e pensei no que poderia estar acontecendo. O tempo ficou lento, aos poucos, voltei ao estado presente.

As sensações passam pelo meu corpo e me afetam, o nervosismo por remexer em tantas coisas que me tocam, como a morte e os esquecimentos, me faz perceber que a fala remetia ao mar e a toda uma intensidade. Lembrar de pessoas que estão próximas e outras que já não estão me paralisa, talvez por ficar evidente naquele momento que nossa existência é só um instante. 
Tentei falar sobre um nó na garganta que me trava e ele me travou, senti um aperto no peito, e uma lentidão no tempo, ele não estava mais passando e o mundo parecia que caía sobre minhas costas. Fiquei zonza, como se meu corpo não estivesse ali, uma disjunção momentânea, talvez pelo calor de verão fora de época, ou muito mais provável pelo que me foi atravessado.

Minha fala, mesmo com a preparação, ficou travada pelas mortes. Esses estímulos foram tão fortes que me travaram momentaneamente durante a performance, mas a percepção que tinha era de uma fala contínua. Como se um não dito tivesse me habitado de tal maneira que me impedia de dizer.

É interessante perceber que cada vez que se passa por memórias se tem contato pela sensação, um causador do efeito verdade, de um dobro de impressão que se encosta, vibrando a estrutura (DELEUZE; GUATTARI, 2011). Esse duplo efeito de experiência, pelo fazer, do encontro com o colega e as inquietações de ambos na performance, foi colocado em relação às coisas - memórias em performance.

A fala veio como memória e como processo, a voz que se engasga ao lembrar. Cortar a roupa é a retirada de camadas, um rasgar recordações que são simbolizadas pela matéria (a própria roupa), objeto que utilizamos para momentos especiais, que neste caso foi a própria performance.

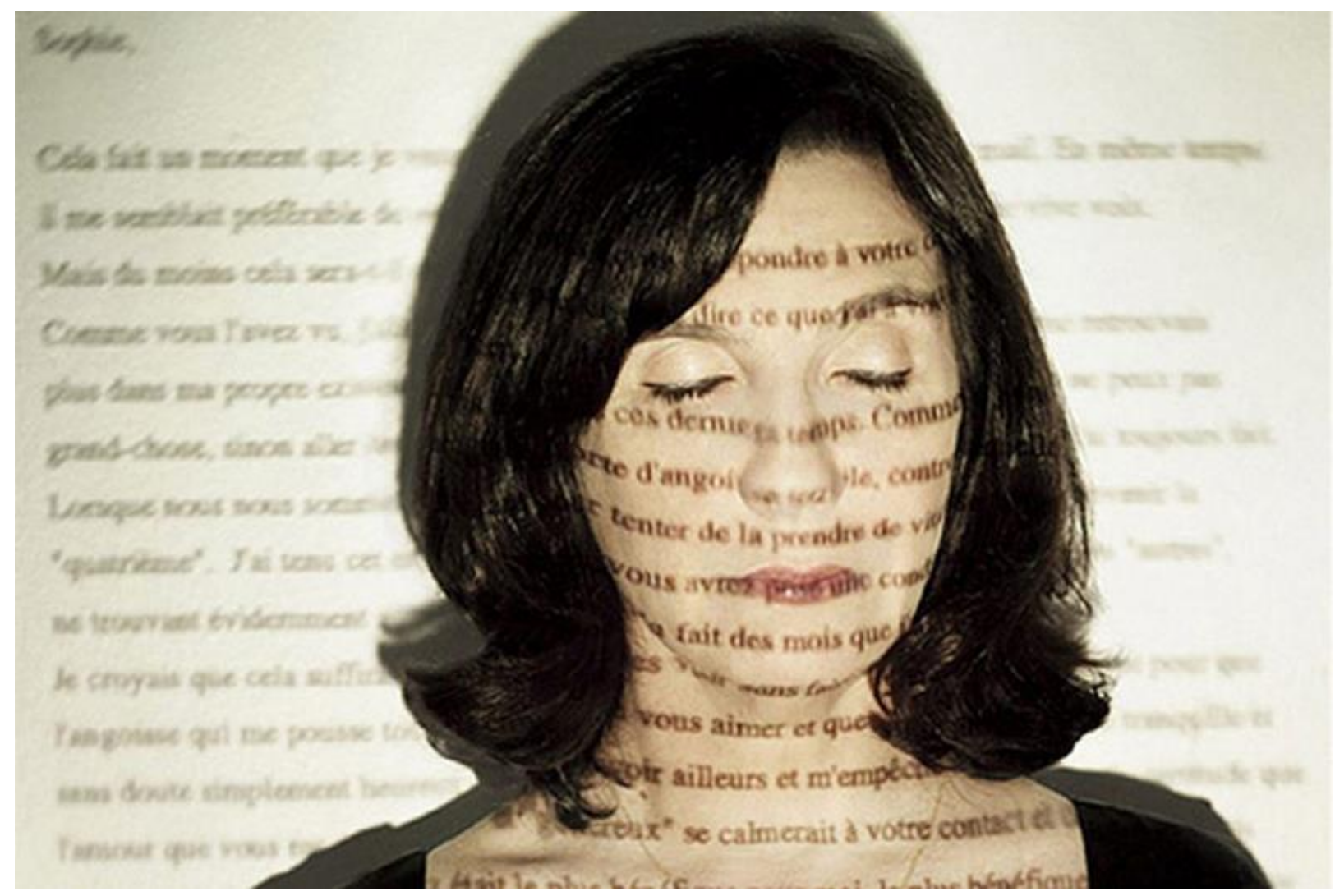

Figura 7: Sophia Calle em sua exposição Cuide de Você, 2009 
A artista Sophia Calle é uma referência para refletir sobre essa performance. Calle, na exposição Cuide de Você (fig. 07), convida pessoas de formação e condições as mais distintas e um papagaio para lerem a carta que recebe de seu ex-companheiro como término de relacionamento. $\mathrm{Na}$ exposição a artista mostra a versão da carta interferida pela análise dessas pessoas, como por exemplo a análise por parte de uma professora de linguística indicando os erros gramaticais.

A evidência de uma conexão entre as situações afetivas, pessoais da artista e a publicização destas por meio da linguagem da arte, como obra, é uma das relações que encontro entre elementos que utilizo em minhas performances. Na performance Voz e Matéria proponho ao artista que performa comigo que divida as angústias das memórias, compartilho com ele a recordação do que perdi com a morte de minha avó e o que me dá um nó na garganta. Esta inquietude que passo durante a performance, através das coisas-memória sendo ditas, coloca-me a pensar sobre aspectos de similitude que esta obra tem com a exposição de Sophia Calle: as experiências de sua vida pessoal colocadas na criação. Em Voz e Matéria também trago estas questões: na fala compartilhada com o colega e com o público. Mesmo que com um volume de voz baixo, coisas não ditas sentem vontade de sair e, me aproximando ainda mais com a artista, penso que a minha também é uma "experiência social da intimidade, do público e do privado, vivida de forma individuada como figura de uma produção subjetiva" (GONÇALVES, 2010, p. 209), que pode colocar a criação em performance a mover o pensamento.

A angústia compartilhada, que para Calle foi uma forma de lidar com a situação de um término amoroso, transforma a situação em arte. Para mim e Lumilan, foi uma forma de dividir os fragmentos destas coisas não ditas que envolvem situações afetivas. Calle investigou o próprio comportamento para criação, "Uma forma de arrumar e dispersar memórias (suas e dos outros) e de rearranjá-las" (GONÇALVES, 2010, p. 209), assim também revivemos coisas que agora ganham formas e contornos, uma memória que vem com mais força para expressar-se como potência.

Para a performance Voz e Matéria, eu não havia pensado em dizer algo que já estava escrito, mas falas que surgissem pela memória. Recortar o vestido preto, uma roupa fúnebre, póstuma à morte de minha avó, possibilitaria fragmentar o sofrimento de sua perda, encarar aos poucos a tristeza de sua falta, tendo a fala como motivador de colocar para fora sentimento de algo não dito ou mesmo deixar que se reverberassem no corpo, nas sensações dos acontecimentos de uma lembrança pura, fazendo-a se tornar memória-hábito. 
Compartilhando a performance, as sensações de algo que afeta se expõem para os outros, o acontecimento por si só reverbera. Tanto nas memórias recentes quanto nas mais antigas vem o nó na garganta; o não conseguir dizer me domina, apenas me expresso sobre a sensação, uma imagem vem a minha cabeça, mas não consigo de forma nítida dizer com palavras o que é.

\section{Considerações Finais}

As Performances $O$ que é daqui? Processos e trajetos e Voz e Matéria trazem à tona relações entre a arte e atravessamentos do cotidiano, das relações afetivas, das lembranças. Ao realizar uma pesquisa, concebo meu "fazer artístico como práxis, portadora de uma dimensão teórica e, consequentemente, articulando o seu fazer de atelier como a produção do conhecimento" (REY, 1996, p. 82). Em minha prática coloquei o fazer em primeiro lugar, entretanto as tramas com alguns conceitos originaram repetições e diferenças, me fazendo compreender que estes são a força para minha ação performática acontecer e gerar novos pensamentos. Na investigação das coisas não ditas, as coisas-memória surgiram em meus textos, como se meu corpo pedisse passagem a essa voz: uma mistura fecunda. As memórias afetivas, que surgem como sensações (BERGSON, 2010) são de família e questões pessoais me ajudam a atualizar o movimento do pensamento. Na prática, minhas memórias irão cruzar as ações performáticas. Elas se transformam em coisas-memória influenciando nos objetos, vestimentas, gestos e contextos que estão presentes na ação. Através das performances, trago à tona relações que habitam em mim, dando-lhes expressão e trazendo à superfície as coisas não ditas que passam a ser compartilhadas.

Este processo de escrita me motivou a pensar sobre minha prática e sobre as pistas que eu ia me colocando ao longo das descobertas. As inquietações sobre como este processo se dá, não só na prática, mas também na teoria, ainda tem muitas coisas não ditas por dizer. Aos poucos, me localizando pelos conceitos, consigo me cercar destes estudos.

Nesta investigação, das coisas não ditas, as coisas-memória surgiram em meus textos, como se meu corpo pedisse passagem a essa voz: uma mistura fecunda.

Para dar conta desta pesquisa tive que estabelecer estratégias, escolhas pontuais entre leituras e práticas, criação das performances, relações sobre o processo, as matérias que estariam à disposição para complementar o percurso, objetos que pudessem me ajudar a potencializar os atos e como as pistas puderam me formar, aparecendo no meu texto. Colocando um caminho de coisas feitas e pausas para o pensamento, faço um resumo de cada performance, pela maneira que foram experienciadas e em que são similares. 
A performance reforça o instante, rompe com a representação, desmitifica a ideia de cena, mostra as ações sem ter a obrigação de agradar, deflagra com as convenções, "essencialmente, a performance é um lugar de reencontro permanente, para quem jamais tomou contato com o que ela experiencia" (GLUSBERG, 2013, p. 103). Assim, pude verificar que o conceito de coisas-memória perpassa e vincula o pensamento em processo com a filosofia atualizando a dimensão prática-afetiva da pesquisa.

\section{Referências}

ABRAMOVIC, Marina. The Lovers: The Great Wall Walk. 1988. Performance. Transitory Objetcs for Human Use. 1991. Série de objetos diversos.

Olympio, 2017. . Pelas Paredes: memórias de Marina Abramovic. Rio de Janeiro: José

ASSOCIAÇÃO CULTURAL VÍDEO BRASIL. Sophie Calle - Cuide de você. Catálogo de exposição. São Paulo, 2009. 28 p.

BERNSTEIN, Ana. A performance solo e o sujeito autobiográfico. Revista Sala Preta, São Paulo, Universidade de São Paulo, v. 1, n. 1, 2001, p. 91-103.

BERGSON, Henri. Matéria e memória: ensaio sobre a relação do corpo com o espírito. São Paulo: Martins Fontes, 2010.

CALLE, Sophie. Sophie Calle: And so forth. Prestel, 2016.

DERRIDA, Jacques. Papel-Máquina. Trad. Evando Nascimento. São Paulo: Estação Liberdade, 2004.

D'ANGELO, Biagio. Suite vénitienne, de Sophie Calle. Viagem autofotobiográfica com sombras, máscaras e mapas de ilusão. Fronteiraz (São Paulo), v. 14, 2015, p. 195-206.

DELEUZE, Gilles; GUATTARI, Félix. Mil platôs: capitalismo e esquizofrenia 2. Vol. 1. São Paulo: Editora 34, 2011.

DELEUZE, Gilles. O Homem, Uma Existência Duvidosa. In: , G.; LAPOUJADE, D.; ORLANDI, L. B. L. A ilha deserta e outros textos e entrevistas (1953-1974). Iluminuras, 2008. Cap.13, p.125-127.

FOUCAULT, Michel. História da Sexualidade, 3: O Cuidado de Si. Rio de Janeiro, PAZ \& TERRA, 2017. 
FUREGATTI, Sylvia Helena. Persona, tempo presente e espacialidade na produção artística de Kaprow, Abramovic e Beuys. In: Anais [recurso eletrônico] do $25^{\circ}$ Encontro da Associação Nacional de Pesquisadores em Artes Plásticas, setembro de 2016, Porto Alegre, 2016, p. 2011-2026.

GLUBERG, Jorge. A arte da performance. São Paulo: Perspectiva, 2013.

GONÇALVES, Fernando. Cuide de você: mediação e estética do jogo em Sophie Calle. Revista FAMECOS, Porto Alegre, v. 17, n. 3, setembro/dezembro, 2010, p. 207-215.

GOLDBEG, Roselee. A arte da performance: do futurismo ao presente. São Paulo: Martins Fontes, 2006.

REY, Sandra. Da prática à teoria: três instâncias metodológicas sobre a pesquisa em poéticas visuais, Porto Arte, Porto Alegre, v.7, n.13, nov.1996, p. 81-95. 